
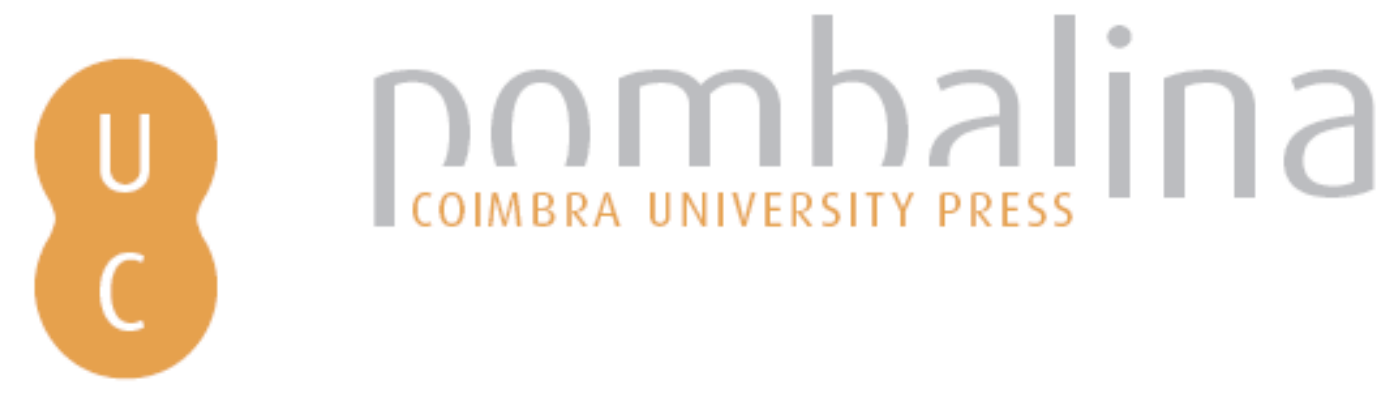

\title{
Poder e eloquência sacra em António Vieira
}

\author{
Autor(es): $\quad$ Pereira, Paulo Silva
}

Publicado por: Imprensa da Universidade de Coimbra

URL

persistente: $\quad$ URI:http://hdl.handle.net/10316.2/38714

DOI: $\quad$ DOI:http://dx.doi.org/10.14195/978-989-26-1164-8_37

Accessed : $\quad$ 26-Apr-2023 13:25:54

A navegação consulta e descarregamento dos títulos inseridos nas Bibliotecas Digitais UC Digitalis, UC Pombalina e UC Impactum, pressupõem a aceitação plena e sem reservas dos Termos e Condições de Uso destas Bibliotecas Digitais, disponíveis em https://digitalis.uc.pt/pt-pt/termos.

Conforme exposto nos referidos Termos e Condições de Uso, o descarregamento de títulos de acesso restrito requer uma licença válida de autorização devendo o utilizador aceder ao(s) documento(s) a partir de um endereço de IP da instituição detentora da supramencionada licença.

Ao utilizador é apenas permitido o descarregamento para uso pessoal, pelo que o emprego do(s) título(s) descarregado(s) para outro fim, designadamente comercial, carece de autorização do respetivo autor ou editor da obra.

Na medida em que todas as obras da UC Digitalis se encontram protegidas pelo Código do Direito de Autor e Direitos Conexos e demais legislação aplicável, toda a cópia, parcial ou total, deste documento, nos casos em que é legalmente admitida, deverá conter ou fazer-se acompanhar por este aviso.

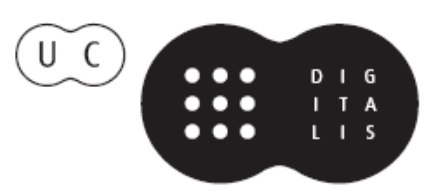




\section{Paulo Silva Pereira}

Universidade de Coimbra / Centro de Literatura Portuguesa

\section{PODER E ELOQUENNCIA SACRA EM ANTÓNIO VIEIRA}

Que a oratória sacra viria a alcançar, no contexto peninsular do Antigo Regime, um lugar de indiscutível relevância enquanto instrumento de intervenção política, pelo seu vigor persuasivo e pela sua capacidade em chegar a largos e heterogéneos setores da sociedade, provam-no abundantes exemplos textuais. De documentos cujo rasto se perdeu no tempo, ou por incúria, ou por deliberada destruição, nada é possível dizer, mas o manancial que chegou até nós, sob forma manuscrita ou impressa, leva-nos a concluir que o Padre António Vieira estaria, por certo, entre as personalidades que melhor souberam tirar partido dessa ação sobre o real contingente. Para além de fatores ligados ao ciclo de produção e consumo do sermão, que o tornavam a um tempo eficaz e aliciante junto do público, para isso concorria - pelo menos nalguns momentos do seu atribulado percurso vivencial - uma íntima proximidade face aos círculos de poder ou, quando tal não sucedia, um travo a injustiça que ajudava a potenciar o poder do verbo. De resto, só pelo desempenho, durante o reinado de D. João IV, do ofício de pregador da Capela Real, com tudo o que isso acarretava em termos de aconselhamento e de propaganda ideológica, estaria, desde logo, implicado na dinâmica de afirmação da soberania monárquica. Apesar de estimulante, a tarefa, como o próprio há de reconhecer no Sermão da Primeira Oitava da Páscoa, de 1647, era ingrata, quando não perigosa, pois «isto de pregar nas cortes, é navegar entre Cila e Caríbdis: ou não haveis de cortar direito, ou haveis de dar a través com o navio».

\footnotetext{
1 Por uma questão de coerência, optámos por citar o texto dos Sermões de Vieira unicamente a partir da edição preparada pelo Padre Gonçalo Alves (1959 [1993]), mas importa sublinhar que está em curso de publicação uma outra sob a direção de Arnaldo do Espírito Santo (Lisboa, Centro de Estudos de Filosofia e Imprensa Nacional - Casa da Moeda) que conta já com dois volumes. O passo do sermão citado encontra-se no vol. II, p. 670.
} 
É hoje perfeitamente visível, depois de trabalhos de fina erudição como os de Margarida Vieira Mendes², o quanto ficaram a dever algumas de suas mais notáveis intervenções no púlpito a certas circunstâncias contextuais, quer relativas ao momento inicial de pregação do sermão, quer ao de compilação e posterior publicação em volume. Na verdade, ora percorrendo o caminho que leva do temporal ao divino, ora em sentido inverso, rara era a vez em que perdia a ocasião (termo já de si intrinsecamente barroco pelo que reflete dessa forma de ser e de estar no mundo própria da época) de comentar a atualidade política, de advertir os mais poderosos e de quem gravitava em seu torno ou de propor soluções efetivas para os problemas existentes. Ao chamar a si o papel de medianeiro entre Deus e os homens, projetando para o exterior a imagem de uma entidade de recorte ético e espiritual mais elevado, o pregador predispunha-se a guiar a comunidade que lhe fora confiada, em questões que transcendiam largamente a esfera espiritual ou religiosa, servindo-se para o efeito de vários momentos do calendário litúrgico, de festividades religiosas ou de cerimónias oficiais que preenchiam o quotidiano da corte. Em momentos de crise ou de fratura - e foram vários os que Vieira teve de superar, para além do mais óbvio: o da Restauração - mais acutilante e necessária se tornava essa missão, como ele próprio soube compreender, ainda que por vezes a coberto de um horizonte de maior envergadura como era o da esperança messiânica ou do sempre louvado amparo divino à gente portuguesa.

O pior que poderia acontecer, contudo, seria perder de vista o alcance que esse circunstancialismo histórico teve ao nível da confeção dos seus sermões, tomando como partes ordenadas (ainda que dispostas ao longo de um continuum temporal) de um todo coerente e sistemático, o que, na raiz, se revestia de caráter fragmentário e pontual. Quando submetidas a rigoroso confronto determinadas opiniões veiculadas em distintos momentos históricos sobre aspetos em grande medida afins, parece emergir um princípio de contradição, mas em boa verdade isso decorre de uma prática acomodatícia superiormente manejada pelo pregador. Nessa medida, convirá desde logo salientar que o estudo que aqui se propõe da crítica de Vieira ao poder procura congregar elementos que

\footnotetext{
2 Como procurou demonstrar sucessivas vezes, "no âmago da arte oratória do padre Vieira e na génese da sua criação discursiva, quer oral quer em livro", encontrava-se quase sempre um persistente lastro de "realismo kairológico» (Mendes, 1989, p. 195).
} 
configuram um denso rastro de reflexão sobre o modo como aquele era exercido, o mérito (ou demérito) de quem o detinha e sobre outras questões tradicionalmente abrangidas pelas "artes de reinar", mas sem incorrer no risco de tentar reconstituir um eventual tratado sobre a matéria.

Da frequência com que o ministério do púlpito acolhia, no século xvir, uma consciência reflexiva sobre o exercício do poder, contribuindo para produzir e reproduzir ideologia em nome de certas franjas do sistema social, dá conta uma das personagens de Hospital das Letras de Francisco Manuel de Melo, quando admite que «nos púlpitos se trata a instrução dos príncipes e ainda a sua emenda com tal igualdade, arte, modéstia e inteireza como se o próprio púlpito fosse o mesmo confessionário, porque o púlpito, se não é confessionário sacramental, é confessionário moral, com uma diferença: que em o primeiro, dizemos as nossas culpas e em o segundo, no-las repreendem em público $»^{3}$. Sem querer, por agora, discutir o alcance prático de conselhos e advertências postos a circular por oradores sacros, alguns deles com reduzida ou até mesmo nula experiência no campo da governação, o certo é que alguns sucumbiam à pressão da audiência que tinham diante de si e que apenas vinha em busca da demonstração do seu engenho, da dimensão espetacular ou do tom agonístico que se alimentava da rivalidade entre ordens religiosas, o que levava a que um ou outro, "desviando-se do seu alto instituto e lembrado do que só devia esquecer-se, arrastar[asse] pelos cabelos os lugares santos e interpretações piedosas da Escritura Sagrada para os fazer cúmplices de seu capricho» ${ }^{4}$.

Por muito esforço que se fizesse no sentido de denunciar a dissimulação, a intriga, a hipocrisia, a adulação e tantos outros perigos que afetavam a vida da corte (o mesmo é dizer do núcleo central do espaço político), poucas alternativas válidas restavam fora dela, pelo que se compreende o empenho posto, sobretudo pelos membros do setor nobiliárquico, na conquista do favor real ou, pelo menos, de uma posição mais vantajosa:

Não sei que influências tem o lado do príncipe, que em todo este elemento em que vivemos, não há parte tão fértil e tão fecunda como aqueles dous pés de terra:

3 Hospital das Letras, p. 116.

4 Hospital das Letras, p. 116. 
tudo ali se dá, tudo ali medra, tudo ali cresce. Crescem os parentes, os amigos, os criados: crescem as honras, os postos, os títulos: cresce a casa, a fazenda, o regalo: cresce o poder, o domínio, o respeito, a adoração, e, sobretudo, cresce a estatura dos mesmos adorados. Ontem pigmeus, hoje homens, amanhã gigantes, e outro dia colossos 5 .

É inegável que isso abria caminho a uma ambição desmedida que ameaçava o princípio de justa recompensa do mérito e era causa de murmuração entre os que se sentiam prejudicados, porque «dar aos que merecem, ou não merecem, é dar; dar só aos que merecem, é premiar. Não fazerem mercês os reis, seria não serem reis: mas hão de fazê-las de maneira que as mercês não sejam dádivas, sejam prémios» ${ }^{6}$. A emergência de perceções históricas e de figurações imagéticas que tendem a apresentar a corte como espaço labiríntico, com a sua significação e complexa organização interna baseada num sistema de códigos sociais, é a prova mais saliente dessa intensa movimentação de interesses divergentes. De facto, para uma certa corrente de literatura áulica produzida em solo peninsular, cada vez mais ativa à medida que avança o século xvir, o modelo do perfeito cortesão de Castiglione (e o âmbito neoplatonizante em que fora gerado) se mostravam cada vez mais ineficazes num mundo em que imperava a rotina do conflito, a rivalidade entre fações e a disputa para conseguir o favor do superior.

Mais do que todas nefasta, segundo se faz notar no Sermão da Primeira Sexta-Feira da Quaresma, pregado na Capela Real em 1651, é uma certa casta de homens que Vieira designa sob a forma de "aduladores de palácio", que "têm as entradas francas, e as chaves tão douradas como as línguas», que "participam os segredos e arcanos da monarquia» e que são os únicos "admitidos a dizer, e a ser ouvidos", pois encobrem a verdade dos factos ao soberano e não querem, por interesse próprio ou falta de coragem, contradizê-lo em decisões menos acertadas que possa tomar?. Não é difícil perceber que esta conceção de serviço do príncipe tinha consequências gravosas para a administração do reino, pois gerava efeitos de distorção da realidade, a tal ponto que se considera que a «adulação é aquele perpétuo mal, ou achaque mortal dos reis, cuja grandeza,

\footnotetext{
5 Sermões, vol. III, p. 1112

6 Sermões, vol. II, p. 680.

7 Sermões, vol. I, p. 772.
} 
opulência e impérios muitas mais vezes destruiu a lisonja dos aduladores, que as armas dos inimigos» ${ }^{8}$. Não por acaso, um dos tópicos mais frequentes numa certa corrente de escrita que projetava um olhar desencantado sobre a corte dizia respeito a esta permanente adaptabilidade do cortesão, com risco da conduta moral, que o tornava próximo da figura do camaleão, o qual «não tendo cor certa nem própria, se reveste e pinta de todas as cores, quaisquer que sejam as do objeto vizinho». Preso na rede de esperanças de aumento de prestígio, aquele é compelido a aceitar as regras de um jogo que tantas vezes contraria o seu íntimo sentir, pelo que no final tudo se assemelha a um coro de vozes em uníssono: «onde as concavidades são muitas, é cena verdadeiramente aprazível ver como os ecos se vão respondendo sucessivamente uns aos outros, e todos sem discrepância dizendo o mesmo" ${ }^{9}$. Não escapa o cortesão à sátira, mas também não sai incólume o rei que tal permite.

Com pouca admiração se pode reconhecer que o modelo de sociedade que se manifesta na parenética vieiriana é ainda fortemente tributário da visão estamental, com os seus estratos bem definidos (ainda que não totalmente cerrados) e hierarquicamente dispostos, conferindo privilégios e obrigações a cada um de seus membros: "Do corpo místico da Monarquia é cabeça o príncipe, porque o peito são os nobres, os pés são o vulgo, os braços os soldados» ${ }^{10}$. Sendo verdade que os nobres apareciam, neste quadro ideológico e social, como mais capacitados para desempenhar as complexas funções do governo do Estado, ou porque dispunham de melhores oportunidades de formação face aos plebeus, ou porque o peso económico das melhores famílias permitia manter com decoro

8 Sermões, vol. I, p. 771.

9 Sermões, vol. I, p. 777-778.

10 Para uma análise mais circunstanciada do sistema social que tomava por modelo, veja-se neste mesmo Sermão de Santo António, pregado na Igreja das Chagas em 1642, o passo seguinte: "Assim como o sal é uma junta de três elementos, fogo, ar e água, assim a república é uma união de três estados, eclesiástico, nobreza e povo. O elemento do fogo representa o estado eclesiástico, elemento mais levantado que todos, mais chegado ao Céu, e apartado da Terra; elemento a quem todos sustentam, isento ele de sustentar a ninguém. O elemento do ar representa o estado da nobreza, não por ser a esfera da vaidade, mas por ser o elemento da respiração, porque os fidalgos de Portugal foram o instrumento felicíssimo, por que respiramos, devendo este reino eternamente à resolução da sua nobreza os alentos com que vive, os espíritos com que se sustenta. Finalmente o elemento da água representa o estado do povo: [...] e não como dizem os críticos, por ser elemento inquieto e indómito, que à variedade de qualquer vento se muda; mas por servir o mar de muitos e mui proveitosos usos à terra, conservando os comércios, enriquecendo as cidades, sendo o melhor vizinho, que a natureza deu às que amou mais.» (pp. 162-163). 
os ofícios que lhes eram atribuídos, nem por isso o pregador deixa de insistir no mérito efetivo de cada candidato. Por mais enraizado que estivesse, no tecido mental da sociedade, o argumento do sangue e do nascimento, Vieira não perdia de vista que a nomeação para destacados postos do exército, para as altas esferas da administração ou para a representação do reino no exterior requeria maior prudência. Por isso mesmo, adverte, no Sermão da Terceira Dominga do Advento que «a verdadeira fidalguia é acção. Ao predicamento da acção é que pertence a verdadeira fidalguia [...] As acções generosas, e não os pais ilustres, são as que fazem fidalgos. Cada um é suas acções, e não é mais, nem menos [...]»11.

Consciente de que pregava verdades que em muito podiam ofender as elites que se encontravam presentes na Capela Real a ouvir o seu Sermão da Terceira Quarta-feira da Quaresma, no ano de 1651, pois teme incorrer no "crime quase de lesa-majestade, por parecer que [...] ou apartava os vassalos do serviço real, ou os exortava a isso", não se coíbe, apesar de tudo, de abordar a problemática do valimento e os malefícios do regime da pretensão ${ }^{12}$. Ao dissecar com grande minúcia cada um dos elementos que compõem o tema bíblico previsto para esse dia (Evangelho de S. Mateus, cap. XX, vers. 20-23), Vieira vai contestando o que considera ser uma petição dirigida a Cristo, por parte de Salomé, para alcançar um cargo proeminente para seus filhos, os apóstolos Tiago e João, mas tendo sempre presente esse "tropel e concurso de pretendentes esfaimados» que inundava os organismos da administração pública com memoriais e petições ${ }^{13}$. «Todos procuram comer, e todos se comem», mas poucos são os que contribuem, de modo efetivo, para o engrandecimento do reino. Em suma, é um quadro de tal forma complexo (a reclamar, por isso, intervenção urgente do soberano) que gera níveis de descontentamento que podem abalar o edifício governativo: «sendo o alvo de todas estas setas envenenadas, os que assistem mais chegados

11 Sermões, vol. I, p. 281. Apostado em fazer valer a exemplaridade ética e moral no âmbito da atuação do indivíduo, mas tendo bem presente a defesa e consolidação do bem comum como pedra angular da sociedade, adverte num outro sermão pregado na Capela Real no ano de 1644, por ocasião da Terceira Dominga do Advento: "[...] os corpos políticos (ou sejam de governo monárquico, ou de qualquer outro que eu entendo geralmente debaixo do nome comum de república), [...] então serão bem servidos, quando os ofícios forem administrados por homens que se escusem deles, isto é, não pelos ambiciosos, senão pelos beneméritos, que não pisam as lamas, nem frequentam os oratórios das cortes, antes fogem e se retiram de as ver, nem se lhes mostrar» (vol. I, p. 309).

\footnotetext{
12 Sermões, vol. I, p. 1093.

13 Sermões, vol. I, p. 1088.
} 
ao trono do supremo poder, os que respondem em seu nome, os que declaram seus oráculos, os que distribuem seus decretos ${ }^{14}$.

A cerca de vinte anos de distância (em 1669), num outro sermão pregado na mesma Capela dos Paços da Ribeira e sob pretexto da mesma circunstância litúrgica, mas quando já se tornara muito diferente a sua condição na corte, Vieira propõe-se oferecer consolação aos «mal despachados», por considerar ser essa "a enfermidade mais geral de que adoecem as cortes, e a dor ou o achaque de que todos comummente se queixam ${ }^{15}$. Uma vez que o tempo político lhe era agora muito mais adverso, pois D. Pedro jamais renovara a confiança e o prestígio de que ele gozara em tempos de D. João IV, para além de outras vicissitudes graves que sofrera entretanto (desterro, processo na Inquisição de Coimbra), não é de todo descabido pensar que o texto possa funcionar como espelho de um estado de alma que também o afetava. No essencial, ainda quando o poder político não conceda o justo prémio pelo desempenho notável em cargos ou missões, não deve haver lugar a desespero, pois «o maior prémio das acções heróicas é fazê-las. O prémio das acções honradas, elas o têm em si, e o levam consigo». Tal argumento, que não era alheio à influência da ética cristã e do pensamento de Séneca, era muito comum não só em tratados de caráter político, mas no campo da epistolografia e noutras manifestações duma escrita autobiográfica que guardava memória de factos relevantes, porque tinha um alcance resgatante para o indivíduo que se sentia menosprezado. Com olhar desenganado, o mesmo é dizer lúcido, faz questão de notar a distância que vai do valor em si, sempre louvável, à pública gratificação, raramente justa: «Se o mundo e o tempo fora tão justo, que distribuíra os prémios pela medida do merecimento, então tínheis muita razão de queixa, porque vos faltava o testemunho da virtude, para que os mesmos prémios foram instituídos. Mas quando as mercês não são prova de ser homem, senão de ter homem, e quando não significam valor, senão valia, pouca injúria se faz a quem se não fazem»" ${ }^{16}$. Pensando seguramente também em si, culpa a pátria de não saber retribuir devidamente o esforço de seus servidores. E, como se todo este trabalho argumentativo não fora suficiente, Vieira sobreleva ainda a força da Providência Divina que tantas vezes acaba por beneficiar quando

\footnotetext{
14 Sermões, vol. I, p. 1088.

15 Sermões, vol. I, p. 1095.

16 Sermões, vol. I, p. 1103.
} 
parecia que apenas castigava e, como tal, o indeferimento da petição, ou qualquer outra forma de injustiça, pode ser visto a uma escala mais abrangente, a da própria salvação do indivíduo ${ }^{17}$.

Sem que alguma vez tenha alcançado, entre nós, o vigor e a importância que conheceu no seio da monarquia dos Habsburgo, à conta do Duque de Lerma e do Conde Duque de Olivares (respetivamente ao serviço de Filipe III e de Filipe IV), a figura institucional do valido ou privado é objeto de alguma atenção, pois podia deliberar, mediante delegação de funções por parte do soberano, em assuntos de grande relevância para o reino e, por norma, tinha na sua dependência uma extensa rede clientelar, com tudo o que isso implicava de reciprocidade de favores e dívidas de amizade. Apenas a governação de Castelo Melhor (por sinal muito perniciosa para Vieira, por se encontrarem em campos políticos opostos) se aproximou em parte desse modelo arquetípico, mas dir-se-ia que o tratamento do tema interessava a Vieira na justa medida em que assim podia configurar um quadro de atuação política eticamente responsável e em absoluta concordância com os princípios da religião. Tal como sucede com outros autores portugueses, mas também espanhóis e italianos, que seguiam uma matriz de pensamento de teor escolástico e procuravam conciliar, de modo harmonioso, um núcleo rígido de preceitos éticos e morais com as exigências reais da política ou, na feliz expressão de António de Sousa Macedo, os «documentos divinos" com as "conveniências de estado", ele reconhece amiúde que tem por missão propor «o que prudentemente ensina a política humana, confirmada mais altamente com os documentos da sagrada»" Não lhe custa reconhecer que "Os supremos príncipes é bem que tenham uma causa segunda, que os represente, e sobre quem descansem» ${ }^{19}$, mas mostra-se cético quanto ao perfil do valido e

\footnotetext{
17 Ocupando, na editio princeps, o lugar imediatamente a seguir aos dois sermões analisados e mantendo com eles inegáveis laços de proximidade, seja pela altura do ano litúrgico (tempo quaresmal), seja pelo local em que foi proferido, estoutro sermão da Terceira Quarta-feira da Quaresma prolonga a temática dos pretendentes, mas desta feita para destacar o modo como o soberano, ou outra instância de poder, recusa ou indefere petições que lhe são dirigidas. Embora apareça com a indicação de 1670 , é muito provavelmente posterior a essa data (talvez mesmo só pronunciado na segunda metade da década), como adianta João Francisco Marques (2009). Não termina Vieira o seu discurso sem refletir ainda sobre o ofício de conselheiro, insurgindo-se contra a eventual substituição de um homem de maduro conselho por outro menos qualificado, no que pode ser visto como invetiva contra a estratégia de poder do regente D. Pedro que não só o excluíra a ele como a outras figuras de alto renome na corte de D. João IV.
}

18 Sermões, vol. I, p. 1156.

19 Sermões, vol. I, p. 1078. 
mais ainda quando tal função é desempenhada por mais de uma pessoa, por gerar opiniões desencontradas. Era tão impressiva a imagem de omnipresença que assim se criava que, não raro, se entendia ser aquele o único intermediário válido entre o monarca e os súbditos, quando não o detentor do próprio poder efetivo. Ora, contrariamente ao que acontecera em França, com Richelieu, e em Espanha, com Olivares, D. João IV soubera evitar esse perigo, como bem demonstra Vieira no Sermão de Exéquias deste "animoso e invicto Pai da Pátria", pois «há reis que nem reinam, nem sabem: eles são os reis, e os seus validos são os que reinam; porque os validos são os que põem e os que dispõem, e os que fazem o que querem; e assim como não reinam, também não sabem; porque nem sabem a quem se dão os prémios, nem sabem por que merecimentos: nem sabem a quem se dão os castigos, nem sabem por que culpas» ${ }^{20}$. Apesar da presença recorrente de figuras e casos de origem bíblica ou retirados da Patrística, o que não surpreende tendo em conta a natureza do seu ofício e a engrenagem retórica que põe em marcha, não se pode dizer que a sua reflexão tenha o mesmo cunho especulativo de tantos outros tratadistas de perfil eclesiástico, porque vai de encontro às preocupações que afligem os membros da comunidade ${ }^{21}$.

Sempre pronto a denunciar injustiças e a tomar partido pelos mais fracos, o pregador procura refletir, em sucessivas ocasiões, sobre a atuação de ministros e sobre o modo como estes se relacionam com a comunidade, pois aí reside um dos pontos fulcrais da paz e da estabilidade do reino: "Os descontentamentos e queixas dos povos ordinariamente caem sobre os ministros, e talvez se levantem

\footnotetext{
20 Sermões, vol. V, p. 1140.

21 Para Francisco Manuel de Melo, por mais ágeis que alguns religiosos se mostrassem no manejo de fontes clássicas e medievais, quantas vezes em atitude reverencial, se não compreendessem o mundo novo que se apresentava diante dos seus olhos - mundo de permanente milícia contra a malícia do homem, segundo propõe o aforismo XIII do Oráculo manual y arte de prudencia de Baltasar Gracián ou em que «a malícia é mais longa que a arte», pois se estende "quase incompreensivelmente", na versão do autor português -, de pouco adiantava a sua reflexão: "Muito autor regular vejo neste catálogo, eu vos confesso que não estou bem com a política inculcada dos religiosos, considerando que suas artes dela não podem ser notórias aos que vivem abstraídos do manejo de negócios profanos; e daqui vem que sempre tive azar com os pregadores quando, por inculcarem do púlpito quatro máximas que os principais já sabem e desprezam, se divertem do seu principal ofício e instituto que é aproveitar às almas e mostrar-lhes o caminho da emenda." (Hospital das Letras, pp. 114-115). Pelo seu percurso vivencial atípico, Vieira conseguia perceber como poucos o valor da experiência no campo da governação, como fica bem patente neste passo: "O político faça-se versado em toda a lição das histórias, e aprenda mais na prática dos exemplos, que na especulação do discurso a resolução dos casos futuros e a experiência dos passados» (Sermões, vol. I, p. 302).
} 
até o sagrado dos príncipes" ${ }^{22}$. Tendo em mente essa delicada missão em prol do bem comum, adverte no Sermão da Primeira Dominga do Advento, de 1650: "Não deixe o ministro de fazer o que tem de obrigação, e pode ser que se salve melhor em um conselho, que em um deserto. Tome por disciplina a diligência, tome por cilício o zelo, tome por contemplação o cuidado, e tome por abstinência o não tomar, e ele se salvará» ${ }^{23}$.

Para muitos homens do século xvis, a corte constituiu, em algum momento da vida, um espaço de deceção, ou por não verem cumpridas as pretensões que acalentavam, ou por considerarem que a ingratidão do poder régio não fazia jus ao empenho demonstrado, quando não por razões de maior gravidade. Não foge a essa regra Vieira, pelo que não causa estranheza que, num ou noutro ponto do seu discurso, deixe vir ao de cima um olhar desencantado, como quando considera, em tom sentencioso, que «o paço a ninguém fez melhor: a muitos que eram bons, fez que o não fossem»²4. É demorado, quando não penoso, esse processo de amadurecimento que conduz o varão justo e virtuoso a projetar sobre a realidade circundante um olhar desenganado (ou mais lúcido), levando-o a encarar, com certa dose de precaução defensiva, a atuação dos vários agentes implicados na órbita do poder e a desmontar a densa trama de interesses e de paixões que subjaz à vivência social. Mas, se muitos concordavam nesta leitura de um mundo intrinsecamente hostil e posto sob o signo de Proteu, por sua essência mudável, nem todos convergiam no programa de ação mais conveniente a aplicar no complexo espaço do poder.

Assim, para o pregador que se dirige, na Quaresma de 1655, ao auditório da "Capela Real e Corte de Lisboa», a primeira e mais substancial lição seria

22 Sermões, vol. II, p. 673.

23 Sermões, vol. I, p. 126. Tendo como pano de fundo os imperativos da consciência cristã e a busca da salvação eterna que também se aplicam aos que governam, não poderia o pregador adotar outro critério de julgamento moral que não o mais exigente, até pelas largas implicações que resultavam das suas decisões: "todo o homem que é causa gravemente culpável de algum dano grave, se o não restitui, quando pode, não se pode salvar: todos ou quase todos os que governam, são causas gravemente culpáveis de graves danos, e nenhum ou quase nenhum restitui o que pode: logo nenhum ou quase nenhum dos que governam se pode salvar» (p. 133).

24 Sermões, vol. I, p. 1088. Por ocasião da sua derradeira partida para o Brasil, nos primeiros anos da década de 80, em função do alheamento da corte e de alguns incidentes que muito o magoaram, como a simulação de um auto-de-fé levada a cabo por estudantes e alguns populares de Coimbra que terminara com a destruição da sua figura em efígie, acusando-o de vendido aos judeus, há de confessar, em tom magoado, ao Marquês de Gouveia, em carta datada de maio de 1682: "Não merecia António Vieira aos portugueses, depois de ter padecido tanto por amor da sua pátria, e arriscado tantas vezes a vida por ela, que lhe antecipassem as cinzas e lhe fizessem tão honradas exéquias.» (Cartas, vol. 3, p. 453). 
a do desengano, de tal forma que pudesse fazer com que muitos, "livres ainda daquelas cadeias que se não podem quebrar», trocassem «a vaidade pela verdade, a corte pelo deserto, o paço pela clausura, as galas pelo cilício, e o cativeiro do mundo pelo jugo suave de Cristo ${ }^{25}$. Sabendo de antemão, contudo, que alguns não podiam (e não queriam) retirar-se para sempre "do povoado e deixar o trato das gentes", propõe uma sábia alternância entre exercício do poder e retiro espiritual, no que acaba por constituir uma inquebrantável (e já esperada) profissão de fé no modelo da "política católica", contra os defensores de correntes de inspiração maquiavelista e tacitista: "No estado secular e político parece que tem menos lugar este retiro, pela frequência e multidão dos negócios, e pela maior necessidade da assistência das pessoas públicas em matérias tantas e de tanto peso, como as que ordinariamente ocorrem no governo de uma monarquia. Assim o supõe a política humana, ou mais verdadeiramente gentílica, como se o acerto dos negócios, por muitos e grandes, necessitara menos da Providência de Deus, e a vista das cousas da Terra, ou no claro ou no escuro, não dependera toda das luzes do Céu!» ${ }^{26}$. Sobre o príncipe pesa, pois, uma dupla determinação, política e religiosa, e só esta última pode impedir a emergência no espaço do poder da astúcia e da dissimulação danosa, exercidas sem qualquer constrangimento ético ou moral: «O trono dos reis tem o seu assento entre Deus e os homens; acima dos homens de quem são superiores, e abaixo de Deus, de quem são súbditos. Para servir e agradar a Deus, o que mais lhe importa, é a santidade: para reger e governar os homens, o que mais hão mister é a prudência» ${ }^{27}$. Num quadro de vigoroso confronto simbólico como o que tem lugar por toda a Europa do séc. XVII, as teses de Vieira procuram contrapor ao paradigma do mudável, do que perpetuamente se oculta, do que engana e dissimula, a substância intemporal, inacessível e sempre igual a si mesma do divino, nas suas múltiplas reverberações.

\footnotetext{
25 Sermões, vol. II, p. 49.

26 Sermões, vol. II, p. 51. Não por acaso, Barbosa Homem, temendo ser mal interpretado, sente a necessidade de distinguir a "Razão de Estado régia", que advoga, da "Razão de Estado tirânica", que atribui a Maquiavel e a todos quantos, de forma mais ou menos direta, se inspiraram no seu pensamento: "A la Regia suelen varios Autores señalar por otros títulos, porque ya la llaman Cristiana, ya Católica, ya justa, ya humana, ya legítima, y otros semejantes nombres, que como se ve, unos sueñan en Religión, otros en racionalidad, y justicia. A la tiránica dan también otros diversos nombres, como son Gentílica, Pagana, Política, Despótica, Leonina, y otros tales, que a respecto contrario de la Regia, tocan a la irreligión o a la injusticia” (apud Torgal e Longobardi Ralha, 1992, p. XX).

27 Sermões, vol. V, Palavra de Deus empenhada no Sermão das Exéquias da Rainha D. Maria Francisca Isabel de Sabóia, p. 1184.
} 


\section{BIBLIOGRAFIA}

MACEDO, A. de Sousa, (1651), Harmonia politica dos documentos divinos com as conveniências de Estado, Na Haga do Conde, Oficina de Samuel Broun.

MARQUES, J. F., (2009), "A crítica sócio-política de Vieira na parénese quaresmal dos sermões dos pretendentes", in Entre a selva e a corte. Novos olhares sobre Vieira, ed. José Eduardo Franco, Lisboa, Esfera do Caos Editores, pp. 61-77.

MELO, F. M., (1970), Le dialogue "Hospital das Letras" de D. Francisco Manuel de Melo. Texte établi d'après l'édition princeps et les manuscrits, variantes et notes de Jean Colomès, Paris, Fundação Calouste Gulbenkian - Centro Cultural Português.

MENDES, M. V., (1989), A oratória barroca de Vieira, Lisboa, Editorial Caminho.

TORGAL, L. R. e RAlHA, R. Longobardi, (1992), João Botero. Da Razão de Estado, Instituto Nacional de Investigação Científica - Centro de História da Sociedade e da Cultura da Universidade de Coimbra, Coimbra.

VALENTE, V. P., (1980), "A Sociedade, o Estado e a História na obra de António Vieira", in Estudos sobre a crise nacional, Lisboa, Imprensa Nacional - Casa da Moeda.

VIEIRA, Padre António, (1971), Cartas, coordenadas e anotadas por J. L. de Azevedo, 3 vols., Imprensa Nacional, Lisboa.

, (1959 [1993]), Sermões, prefaciados e revistos pelo Rev. ${ }^{\text {mo }}$ Padre Gonçalo Alves, Porto, 5 vols., Lello e Irmão Editores.

, (2010), Sermões, direcção, fixação do texto e aparato crítico de A. do Espírito Santo, Lisboa, Centro de Estudos de Filosofia e Imprensa Nacional - Casa da Moeda, vol. I (2008), vol. II. 